\title{
A Theory of Financing Constraints and Firm Dynamics.
}

\author{
Gian Luca Clementi ${ }^{\dagger} \quad$ Hugo A. Hopenhayn ${ }^{\ddagger}$
}

This Version: May 2002

\begin{abstract}
There is widespread evidence supporting the conjecture that borrowing constraints have important implications for firm growth and survival. In this paper we model a multi-period borrowing/lending relationship with asymmetric information. We show that borrowing constraints emerge as a feature of the optimal long-term lending contract, and that such constraints relax as the value of the borrower's claim to future cash-flows increases. We also show that the optimal contract has interesting implications for firm dynamics. In agreement with the empirical evidence, as age and size increase, mean and variance of growth decrease, firm survival increases, and the sensitivity of investment to cash-flows declines.
\end{abstract}

Key words. Optimal Contract, Borrowing Constraints, Moral Hazard, Survival.

JEL Codes: D82, G32, L14.

*We are grateful to Fernando Alvarez, Jeff Campbell, V.V. Chari, Rick Green, Burton Hollifield, and to seminar participants at Bocconi, Bologna, Carnegie Mellon, Di Tella, Humboldt, Iowa, London Business School, Maryland, Minneapolis Fed, Montréal, Penn State, Princeton, Rochester, San Andres, University College London, UT Austin, Washington University in St. Louis, Wharton, the 1999 meeting of the Midwest Economic Association in Nashville, the 1999 Meeting of the Society for Economic Dynamics in Alghero, the Econometric Society 2000 Winter Meeting in Boston, the 2001 conference of the Society for the Advancement of Economic Theory in Ischia, the 2002 SITE Workshop at Stanford, the 2002 Meeting of the European Economic Association in Venice, and the 2003 Meeting of the American Finance Association in Washington, DC. A previous version of this paper circulated under the title "Optimal Lending Contracts and Firms' Survival with Moral Hazard". All remaining errors are our own responsibility. Hopenhayn gratefully acknowledges financial support from the National Science Foundation Grant No. SBR-0110946l.

$\dagger$ Department of Economics, Stern School of Business, New York University. E-mail: gclement@stern.nyu.edu. Web: http://pages.stern.nyu.edu/〜 gclement

${ }^{\ddagger}$ Department of Economics, University of Rochester, and Departamento de Economia, Universidad Torcuato Di Tella. E-mail: huho@troi.cc.rochester.edu. Web: http://econ.rochester.edu/Faculty/Hopenhayn.html 


\section{Introduction.}

There is considerable evidence suggesting that financing constraints are important determinants of firm dynamics. ${ }^{1}$ Such constraints may arise in connection to the financing of investment opportunities faced by firms or temporary liquidity needs, such as those required to survive a recession. This paper develops a theory of endogenous financing constraints and studies its implications for firm growth and survival. In our model, borrowing constraints arise as part of the optimal design of a lending contract under asymmetric information.

The model is as follows. At time zero the borrower (entrepreneur) has a project that requires a fixed initial investment. Once in operation, the project yields revenues that are subject to i.i.d. shocks and increase with the amount of working capital advanced in the period. The project can be discontinued at anytime, providing a fixed liquidation value. A lender finances the initial investment and provides for working capital. Both the borrower and the lender are risk neutral and discount future cash-flows at the same rate. Informational asymmetries arise as the lender cannot monitor either the use of funds or the outcome of the project. We study the optimal dynamic contract subject to the incentive compatibility and limited liability constraints.

The environment is chosen so that in the absence of asymmetric information, the outcome is trivial: there exists an efficient level of working capital which is advanced every period. There is neither growth nor exit. In contrast, with asymmetric information the optimal contract determines non-trivial stochastic processes for firm size (working capital invested), equity (the entrepreneur's share of total firm value), and debt (the lender's share). These processes have two absorbing states: either the firm is liquidated, or a point is reached where borrowing constraints cease to bind and the firm attains its efficient size.

\footnotetext{
${ }^{1}$ Fazzari, Hubbard and Peterson [15], Gilchrist and Himmelberg [18], and Whited [31] among others, find that at the firm level capital expenditures respond positively to innovations in the cash flow process, even after controlling for measures of the expected marginal return on investment. Gertler and Gilchrist [17] argue that liquidity constraints may explain why small manufacturing firms respond more to a tightening of monetary policy than do larger manufacturing firms. PerezQuiros and Timmermann [24] show that in recessions smaller firms are more sensitive to the worsening of credit market conditions as measured by higher interest rates and default premia. For surveys see Hubbard [21] and Stein [29].
} 
Revenue shocks affect the financial structure of the firm and thus have persistent effects on firm size, growth, and probability of survival. As in all models of moral hazard, rewards and punishments serve to discipline the conduct of the entrepreneur. This explains why the value of equity (i.e. the expected discounted value of the cash flows accruing to the entrepreneur) increases with high revenue shocks and decreases with low ones. Moreover, the spread between future contingent equity values increases with the amount of working capital advanced. This mimics the standard moral hazard problem of unobserved effort, where higher sensitivity of a worker's compensation to output is needed if higher effort is required. Due to the interaction of limited liability and a concave profit function, in our model the total value of the firm is a concave function of the entrepreneur's equity. As a result, a spread in future equity is costly. This accounts for the borrowing constraints. A sequence of good shocks results in an increasing path for equity. As its value approaches a threshold, working capital (firm size) eventually increases to the unconstrained efficient level. On the other hand, a sufficiently long sequence of bad shocks leads equity value to a region of liquidation. We find that in the neighborhood of this region risk taking is encouraged, and capital advancements can also be larger.

In spite of its simplicity, the model seems to match most of the qualitative properties of firm dynamics that have been recently documented. In average, investment (change in the working capital invested in the project) is sensitive to innovations in the cash flow process. This sensitivity decreases with age and size. Firm size increases with age; survival increases with firm size; hazard rates for exit increase initially and then decrease with the age of the firm; mean and variance of the growth rate decrease with size and age. ${ }^{2}$

\footnotetext{
${ }^{2}$ All of these facts have been widely documented. Caves provides a comprehensive survey of the literature. Gertler and Gilchrist [17] and Gilchrist and Himmelberg [18] find that the sensitivity of investment to cash-flow is higher for smaller and younger firms. Dunne, Roberts, and Samuelson [13] and Troske [30] document the positive association between age and size. Evans [14], Hall [20], and Troske [30] report the negative correlation between age, size, and the mean and variance of growth. Evans [14] and Dunne, Roberts, and Samuelson [12] provide evidence in favor of the existence of the mentioned relationship between age, size, and survival probabilities. Finally, Andretsch [5] and Baldwin [6] provide evidence that hazard rates are decreasing with age. Bruderl, Preisendorfer, and Ziegler [9] are the only one able to measure hazard rates by month. They find that hazard rates increase for most of the first year and decline thereafter.
} 
Incentive compatibility and limited liability constraints imply a set of feasible debt/equity values. The Pareto frontier of this set defines implicitly the value of equity as a decreasing function of debt. Values on the frontier can be implemented by one-period contingent contracts and debt rollover. There is some debt forgiveness when low shocks occur. The lender is compensated for this loss when high shocks are realized. There is also a maximum sustainable debt, which corresponds to the lowest value of equity on the Pareto frontier. Two possible cases can arise, depending on whether this equity value is zero (the smallest feasible value) or greater than zero. In the first case, the contract is renegotiation-proof and the maximum level of debt is equal to collateral of the project (i.e. its liquidation value). In the second case, the maximum level of debt exceeds the value of the collateral. The first case occurs for high levels of liquidation value while the second occurs for low ones.

Our work builds on recent contributions by Gertler [16] and Bolton and Scharfstein [8]. Gertler [16] studies the optimal contract between a lender and a borrower in a three-period production economy with asymmetric information. Similarly to ours, in Gertler's model the tradeoff between current employment and "ex-post financial position" induces borrowing constraints and investment-cash flow sensitivity. A shortcoming of this model, as pointed out by Gertler, "is that it lies well short of a fully dynamic framework to be matched to the data." Our work is a move in that direction and can be viewed as a dynamic extension of Gertler's - with a minor difference in the timing of the allocation of capital. In addition, our model introduces a positive liquidation value and derives implications for firm survival. Bolton and Scharfstein [8] consider a two-period model with asymmetric information similar to ours, but without a choice of scale. In their scenario, either the project is funded or not. The threat of not providing funds in the second period (i.e. the threat of liquidation) provides incentives for truthful reporting in the first one. As in our model, moral hazard can lead to inefficient liquidation.

The two studies that are most closely related to ours are working papers by DeMarzo and Fishman [11] and Quadrini [25]. Both of these papers consider optimal long-term lending contracts in environments characterized by asymmetric information. DeMarzo and Fishman [11] focus on the implementation of the long- 
term arrangement by means of simple contracts, while Quadrini [25] characterizes renegotiation-proof contracts.

The effects of moral hazard on investment when long-term lending contracts are allowed, have also been investigated by Atkeson [3] and Marcet and Marimon [23]. Atkeson shows that asymmetric information and limited enforcement considerations can explain why developing countries experience capital outflows when hit by bad idiosyncratic shocks. Marcet and Marimon study the effects of the same imperfections on capital accumulation.

In recent work, Albuquerque and Hopenhayn [1] study lending and firm dynamics in a model with limited enforcement. In spite of the similarities between our approach and theirs, some of the implications are radically different. To illustrate this point, Section 9 considers a variant of our model where moral hazard is replaced by incomplete enforcement. In contrast to the moral hazard case, the entrepreneur's equity and firm size never decrease and there is no exit.

Our model is one of repeated moral hazard. The recursive representation that we use was developed by Green [19] and Spear and Srivastava [28]. The pioneering work in the area goes back to Radner [26] and Rogerson [27].

The remainder of this paper is organized as follows. The model is introduced in Section 2. In Section 3 we characterize the main properties of the optimal contract. In particular, we describe the optimal capital advancement and repayment policies, and the evolution of equity over time as implied by the contract. The implications for firm growth survival are described in Section 4. In Section 5 we consider the implementation of the optimal lending contract by means of short-term loans. Section 6 discusses the role of collateral. In Section 7 we consider the financial feasibility of the optimal contract. Section 8 shows that there is an equivalent formulation if it is the use of funds, rather than realized revenues, that cannot be monitored. In Section 9 we provide the comparison with the incomplete enforcement model. Section 10 concludes. 


\section{The Model.}

Time is discrete and the time horizon is infinite. At time zero the entrepreneur has a project which requires a fixed initial investment $I_{0}>0$ and a per-period investment of working capital. Let $k_{t}$ be the amount of working capital invested in the project - its scale - in period $t$. The project is successful with probability $p$, in which case the entrepreneur collects revenues $R\left(k_{t}\right)$. If the project fails, revenues are zero. We assume that the function $R$ is continuous, uniformly bounded from above, and strictly concave. At the beginning of every period the project can be liquidated. The liquidation generates a scrap value $S$.

We assume that the lender cannot observe the revenue outcome. In other words, such outcome is private information for the entrepreneur. ${ }^{3}$

The entrepreneur's net worth is given by $M<I_{0}$. Therefore, to undertake the project, he requires a lender (bank) to finance part of the initial setup cost and the project investments in every period. We assume that in every period the entrepreneur is liable for payments to the lender only to the extent of current revenues. Therefore the firm is restricted at all times to a nonnegative cash flow. ${ }^{4}$

Both the borrower and the lender are risk neutral, discount flows using the same discount factor $\delta \in(0,1)$, and are able to commit to a long term contract.

We model the relation between the bank and the entrepreneur as a message game. At time 0 the bank makes a take-it-or-leave-it offer to the entrepreneur. The offer consists of a contract whose terms can be contingent on all public information. Let $\theta$ be a Bernoulli random variable, with $\theta \in \Theta \equiv\{H, L\}$ and $\operatorname{prob}\{\theta=H\}=p$. Revenues are positive (and equal to $R(k)$ ) when $\theta=H$, and identically zero when $\theta=L$. We invoke the Revelation Principle to reduce the message space to the set $\Theta$. Thus a reporting strategy for the entrepreneur is given by $\hat{\boldsymbol{\theta}}=\left\{\hat{\theta}_{t}\left(\theta^{t}\right)\right\}_{t=1}^{\infty}$, where $\theta^{t}=\left(\theta_{1}, \ldots, \theta_{t}\right)$.

The dynamic contract specifies cash-flow and liquidation policies which are contingent on all information provided by the agent. Letting $h^{t}=\left(\hat{\theta}_{1}, \ldots, \hat{\theta}_{t}\right)$ denote the history of reports of the agent, the contract $\boldsymbol{\sigma}=\left\{\alpha_{t}\left(h^{t-1}\right), Q_{t}\left(h^{t-1}\right), k_{t}\left(h^{t-1}\right), \tau_{t}\left(h^{t}\right)\right\}$

\footnotetext{
${ }^{3} \mathrm{An}$ alternative formulation where revenue is observable but the use of funds (or investment) cannot be monitored is considered in section 8. The two formulations turn out to be equivalent.

${ }^{4}$ This assumption can be easily relaxed to a lower bound.
} 
specifies a contingent policy of liquidation probabilities $\alpha_{t}$, transfers $Q_{t}$ from the lender to the entrepreneur (in case of liquidation), capital advancements $k_{t}$ and transfers $\tau_{t}$ from the entrepreneur to the lender (in case of no liquidation).

The timing is the same at every information node (i.e. after every history $h^{t}$ ) and is described in Figure 1. At the beginning of the period, the lender has the chance of liquidating the project. The contract dictates that he will do so with probability $\alpha_{t}\left(h^{t-1}\right)$. In case liquidation occurs, the entrepreneur is compensated with a value $Q_{t}\left(h^{t-1}\right)$, while the lender receives $S-Q_{t}\left(h^{t-1}\right)$. If the project is not liquidated, the lender provides the entrepreneur with capital $k_{t}\left(h^{t-1}\right)$. Thereafter, the entrepreneur observes the revenue realization and makes a report to the lender. The lender will require a transfer $\tau_{t}\left(h^{t}\right)$, where $h^{t}=\left(h^{t-1}, \hat{\theta}_{t}\right)$.

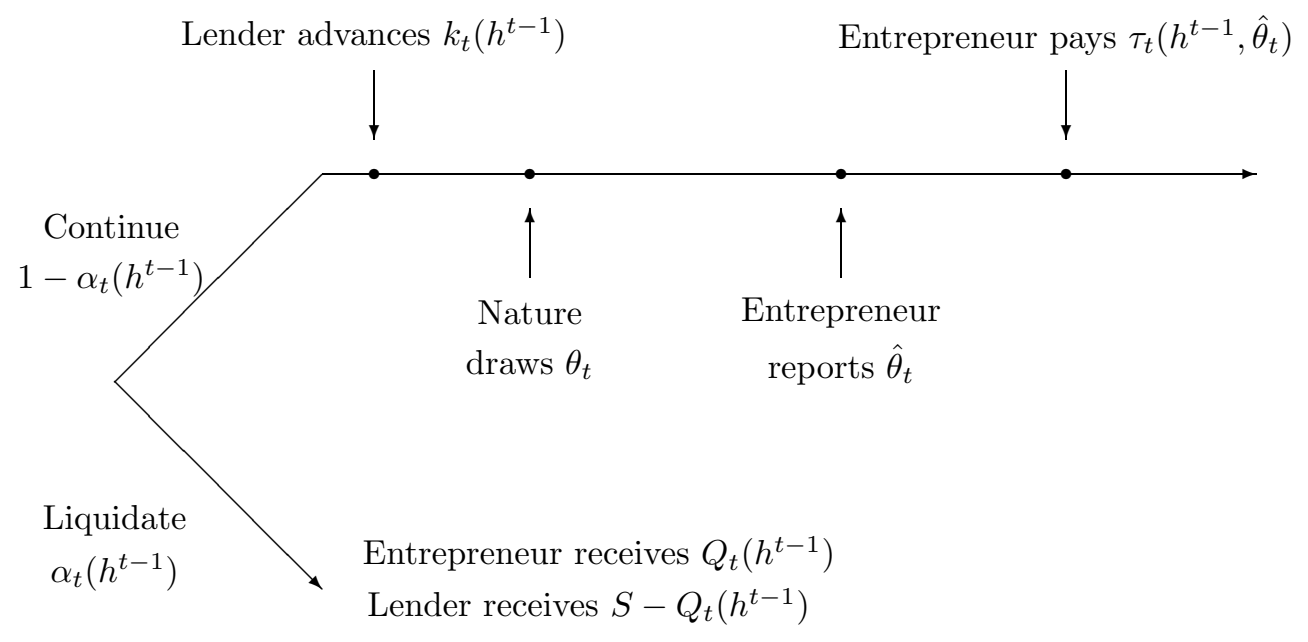

Figure 1: The Timing.

At every time $t$, conditional on success, the entrepreneur will receive a net cashflow $R\left(k_{t}\right)-\tau_{t}$. We assume, without loss of generality, that these resources are fully consumed by the entrepreneur (i.e. not reinvested in the business venture). ${ }^{5}$ As a consequence, the nonnegativity constraint on entrepreneur's cash-flows requires that $\tau_{t} \leq R\left(k_{t}\right)$. When the project fails no payments are made to the bank. We are

\footnotetext{
${ }^{5}$ Alternatively, we might allow the entrepreneur to save and assume that the bank can observe the return on his wealth and monitor the size of the project.
} 
now in the position to provide our definition of feasible contract.

Definition 1 A contract $\boldsymbol{\sigma}$ is feasible if $\forall t \geq 1$ and $\forall h^{t-1} \in \Theta^{t-1}$

(i) $\alpha_{t}\left(h^{t-1}\right) \in[0,1]$,

(ii) $Q_{t}\left(h^{t-1}\right) \geq 0$,

(iii) $\tau_{t}\left(h^{t-1}, H\right) \leq R\left(k_{t}\left(h^{t-1}\right)\right)$,

(iv) $\tau_{t}\left(h^{t-1}, L\right) \leq 0$.

After every history $h^{t-1}$, the contract and reporting strategies $(\boldsymbol{\sigma}, \hat{\boldsymbol{\theta}})$ imply expected discounted cash flows for the entrepreneur and the lender. Denote such values as $V_{t}\left(\boldsymbol{\sigma}, \hat{\boldsymbol{\theta}}, h^{t-1}\right)$ and $B_{t}\left(\boldsymbol{\sigma}, \hat{\boldsymbol{\theta}}, h^{t-1}\right)$, respectively. These also correspond to the values of equity and debt.

Definition 2 A contract $\boldsymbol{\sigma}$ is incentive compatible if $\forall \hat{\boldsymbol{\theta}}, \quad V_{1}\left(\boldsymbol{\theta}, \boldsymbol{\sigma}, h^{0}\right) \geq V_{1}\left(\hat{\boldsymbol{\theta}}, \boldsymbol{\sigma}, h^{0}\right)$.

Now define the set $\mathcal{V} \equiv\left\{V \mid \exists \boldsymbol{\sigma}\right.$ s.t. (feas), (ic) and $\left.V_{1}\left[\boldsymbol{\sigma}, \boldsymbol{\theta}, h^{0}\right]=V\right\} . \mathcal{V}$ is the set of equity values that can be generated by feasible and incentive compatible contracts. ${ }^{6}$ For any $V \in \mathcal{V}$, an optimal contract maximizes the value obtained by the lender (and thus total value) among all incentive compatible and feasible contracts that deliver the entrepreneur an initial value $V$. This defines a frontier of values

$$
B(V)=\sup \left\{B \mid \exists \boldsymbol{\sigma} \text { s.t. } V_{1}\left[\boldsymbol{\sigma}, \boldsymbol{\theta}, h^{0}\right]=V \text { and } B_{1}\left[\boldsymbol{\sigma}, \boldsymbol{\theta}, h^{0}\right]=B\right\} .
$$

Every point on the frontier corresponds to a capital structure $(V, B(V))$. The corresponding total value $W(V)$ is a function of the capital structure, as $W(V)=$ $V+B(V)$. In the remainder of this paper we characterize the set of contracts yielding values on the frontier.

\subsection{A Benchmark: Contracts under Symmetric Informa- tion.}

As a first step, it is useful to consider the case of symmetric information, where the lender observes the revenue realizations and can write contracts contingent on them. Since the two agents discount cash flows at the same rate, the optimal contract

\footnotetext{
${ }^{6}$ As shown below, there is an incentive compatible and feasible contract for any $V \geq 0$.
} 
will maximize the total expected discounted profits for the match. This result is achieved by having the lender provide the entrepreneur with the unconstrained efficient amount of capital in every period.

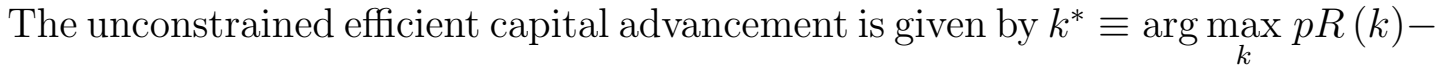
$k$ and implies a per-period total surplus $\pi^{*} \equiv \max _{k} p R(k)-k$. Then, the total surplus is given by $\widetilde{W} \equiv \frac{\pi^{*}}{1-\delta}$. Undertaking the project is optimal as long as $\widetilde{W}>I_{0}$. Once started, the firm will never grow, shrink, or exit. Any division of the surplus $\widetilde{W}$ among the lender and the entrepreneur is feasible, provided that the latter obtains a nonnegative value.

\subsection{The Contract with Private Information: a Recursive Representation.}

In any lending contract, the evolution of equity satisfies the following accounting identity:

$$
V_{t}=p\left(R\left(k_{t}\right)-\tau_{t}\right)+\delta\left[p V_{t+1}^{H}+(1-p) V_{t+1}^{L}\right]
$$

where the first term on the right-hand side corresponds to expected dividends and the second to the expected continuation value. The quantities $V_{t+1}^{H}$ and $V_{t+1}^{L}$ are the continuation values contingent on high and low report, respectively. Equation (1) suggests a tradeoff in the assignment of values over time and across states. These are precisely the margins considered in the optimal contract design.

The above observations also suggest a recursive representation of the optimum problem defined in the previous section. ${ }^{7}$ The state variable for the problem is the entrepreneur's value entitlement at the beginning of a period, $V$. The first choice to be made is whether to liquidate the project, obtaining the value $S$, or keep it in operation.

We start by defining the total value of the firm in case the project continues. The flow equation (1) becomes now a constraint, as the initial value $V$ must be delivered

\footnotetext{
${ }^{7}$ Green [19] and Spear and Srivastava [28] were the first to show that, under mild boundedness conditions, there exists a recursive formulation for the maximization problem faced by the principal in models of repeated moral hazard. Such conditions hold in our case. We decide to omit the proof of equivalence between the sequence problem and the recursive problem, because it consists of the mere application of the techniques used by Atkeson and Lucas [4], among the others.
} 
to the entrepreneur by the continuation contract. Suppressing time subscripts, this gives:

$$
V=p(R(k)-\tau)+\delta\left[p V^{H}+(1-p) V^{L}\right]
$$

As usual, the only relevant incentive constraint is the one imposing truthful reporting in the high state:

$$
R(k)-\tau+\delta V^{H} \geq R(k)+\delta V^{L} .
$$

By reporting truthfully, the entrepreneur obtains dividends $R(k)-\tau$ in the current period and a continuation value $V^{H}$. By reporting a low state, the agent avoids making any repayment and thus increases dividends at a cost of a lower continuation value. The incentive compatibility condition can be rewritten as

$$
\tau \leq \delta\left(V^{H}-V^{L}\right)
$$

Finally, the limited liability constraint requires that

$$
\tau \leq R(k)
$$

A continuation value $V^{i}(i=H, L)$ must be supported by a feasible continuation contract. Any positive continuation value $V^{i} \geq 0$ is feasible, as it can be implemented by giving the entrepreneur no capital and a transfer equal to $V^{i}$, and then liquidating the project. Any continuation value $V^{i}<0$ is not feasible, for it would violate the limited liability constraint (4) in some future period. Hence, a value $V$ can be supported by a feasible contract if and only if $V \geq 0$.

We denote firm value contingent upon continuation as $\widehat{W}$. This is different from the value of the firm prior to the liquidation decision, which is denoted as $W$. The choice variables are the capital advancement for the period $k$, the repayment $\tau$, and the contingent continuation values $V^{H}$ and $V^{L}$. The value $\widehat{W}(V)$ is given by

$$
\begin{aligned}
\widehat{W}(V)= & \max _{k, \tau, V^{H}, V^{L}}[p R(k)-k]+\delta\left[p W\left(V^{H}\right)+(1-p) W\left(V^{L}\right)\right] \\
& \text { subject to }(2),(3),(4) \\
& \text { and } V^{H}, V^{L} \geq 0 .
\end{aligned}
$$


The first term of the maximand corresponds to the current period's expected profits. The second term indicates the expected discounted total value of the firm at the beginning of the following period, prior to the liquidation decision.

We now turn to the liquidation decision. Due to the non-convexity introduced by a positive liquidation value, a stochastic liquidation decision may be optimal in some states. Allowing for randomizations over the liquidation decision is equivalent to assuming that at the beginning of every period the lender offers a lottery to the borrower. The firm is liquidated with probability $\alpha$, in which case the borrower receives $Q$, and it is kept in operation with probability $1-\alpha$. In the latter case, the borrower receives $V_{c}$, where $c$ is mnemonic for continuation. Then, the function $W(V)$ solves the following functional equation:

$$
\begin{aligned}
W(V)= & \max _{\alpha \in[0,1], Q, V_{c}} \alpha S+(1-\alpha) \widehat{W}\left(V_{c}\right) \\
& \text { subject to } \alpha Q+(1-\alpha) V_{c}=V, \\
& \text { and } Q, V_{c} \geq 0 .
\end{aligned}
$$

Figure 2 illustrates the basic features of the value function. Following standard dynamic programming arguments, it is easy to show that the $W(V)$ is concave and increasing. The domain of $V$ can be partitioned in three regions: (i) a randomization region, $0 \leq V \leq V_{r}$; (ii) a region where there is no current liquidation and total firm value increases with the entitlement of the entrepreneur, $V_{r} \leq V \leq \widetilde{V}$; (iii) a region where the total value of the firm equals the value under symmetric information, $V \geq$ $\widetilde{V}$. We examine each region in turn.

First note that if $V=0$ at the liquidation stage, the project is scrapped for sure, providing a total value $W(0)=S$. If the firm were not liquidated and $V=0$, no capital could be advanced in the current period and the firm would be liquidated for sure the following period, so $\widehat{W}(0)=\delta S$. For values $0<V \leq V_{r}$, it is optimal to give the entrepreneur a lottery with values of $Q=0$ in case of liquidation and $V_{c}=V_{r}$ in case of continuation. The total value of the firm in this region is given by a linear 


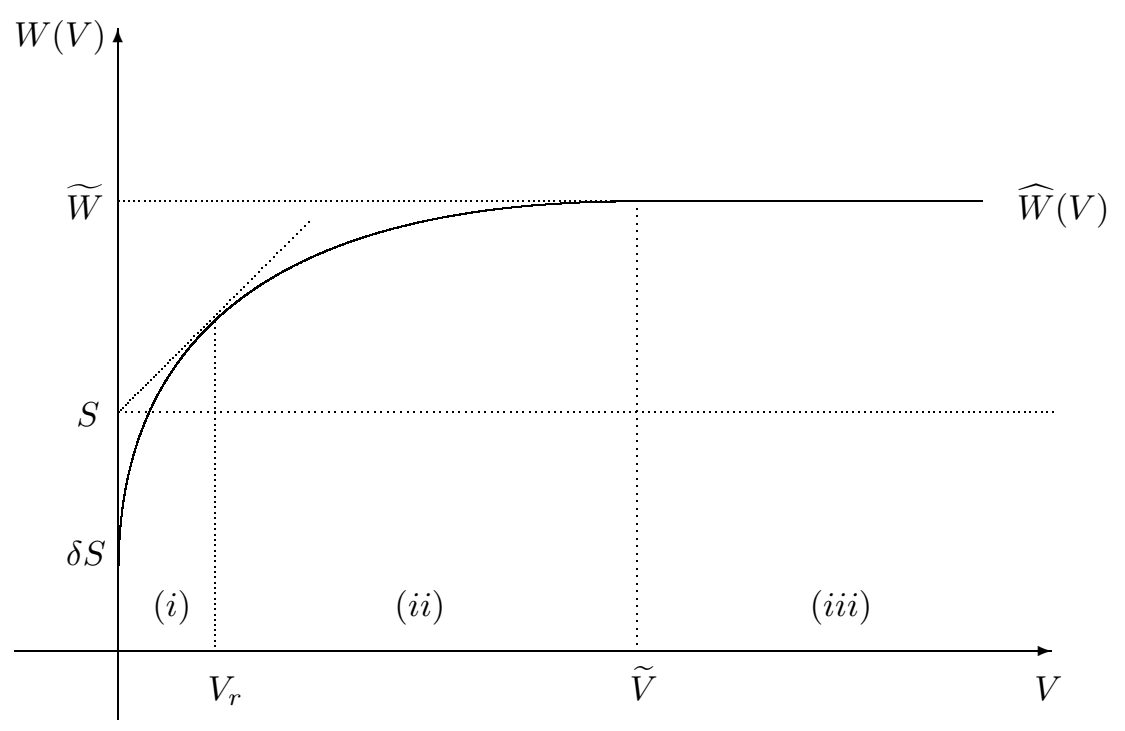

Figure 2: The Value Function.

combination of $S$ and $\widehat{W}\left(V_{r}\right)$, with weights $\alpha(V)$ and $(1-\alpha(V))$, respectively. The probability of liquidation is $\alpha(V)=\left(V_{r}-V\right) / V_{r}$. Notice that for $V \leq V_{r}$ such probability is decreasing in the entrepreneur's value entitlement.

Consider now region (iii), where borrowing constraints cease to bind. The threshold $\widetilde{V}$ is defined as the minimum entitlement such that the policy of providing every period the optimal advancement $k^{*}$ is incentive compatible. The value $\widetilde{V}$ can be derived from the following necessary conditions:

$$
\begin{gathered}
\widetilde{V}=p\left(R\left(k^{*}\right)-\tau\right)+\delta\left(p V^{H}+(1-p) V^{L}\right), \\
\tau \leq \delta\left(V^{H}-V^{L}\right), \\
V^{L} \geq \widetilde{V}, V^{H} \geq \widetilde{V} .
\end{gathered}
$$

The smallest value that satisfies these constraints is obtained when the incentive compatibility constraint binds and $V^{L}=\widetilde{V}$. Substituting in the first equation, we obtain

$$
\widetilde{V}=\frac{p R\left(k^{*}\right)}{1-\delta} .
$$

Notice that this value entitlement can be implemented by giving the entrepreneur the efficient capital advancement $k^{*}$ in every period, with no need of repayment. This also corresponds to a situation where the entrepreneur has a positive balance equal to $k^{*} /(1-\delta)$ in the bank at an interest rate $r=(1-\delta) / \delta$. Such balance is exactly enough to finance the project at full scale in all contingencies. 
The results proved in this section are summarized in the following Proposition. ${ }^{8}$

Proposition 1 The value function $W(V)$ is increasing and concave. There exists values $0<V_{r}<\widetilde{V} \equiv \frac{p R\left(k^{*}\right)}{1-\delta}$, such that:

1. The firm is liquidated with probability $\frac{\left(V_{r}-V\right)}{V_{r}}$ when $V \leq V_{r}$;

2. $W(V)$ is linear for $V<V_{r}$, strictly increasing for $V<\widetilde{V}$ and equal to $\widetilde{W}$ for $V \geq \tilde{V}$.

\section{Properties of the Optimal Lending Contract.}

This section characterizes the provisions of the optimal contract when $V \in\left[V_{r}, \widetilde{V}\right)$ ( region (ii) ). We start with a general proposition that shows that in this region borrowing constraints bind.

Proposition 2 i) The optimal capital advancement policy $k(V)$ that solves (P1) is single valued and continuous. ii) $V<\widetilde{V}$ implies $k(V)<k^{*}$; (iii) $V \geq \widetilde{V}$ implies $k(V)=k^{*}$.

Although this result does not depend on a particular repayment policy, its economic intuition is clearest in the case in which $\tau=R(k) \cdot{ }^{9}$ Lemma 1 shows that when this is the case, the incentive compatibility constraint (3) binds for all $V<\widetilde{V}$. Therefore the level of capital advancement is tied to the spread in equity values $\left(V^{H}-V^{L}\right)$. Due to the concavity of $W(V)$ this spread is costly so that $k<k^{*}$ unless the value function $W$ is flat in the relevant portion.

\subsection{Optimal Repayment.}

As the total value of the firm increases with $V$, there is an efficiency gain in delaying dividend distribution. Given that both agents are risk-neutral and discount future cash-flows at the same rate, the optimal repayment schedule is the one that allows the equity value $V$ to reach the threshold $\widetilde{V}$ in the shortest possible time. Setting

\footnotetext{
${ }^{8}$ The proofs not included in the body of the paper can be found in Appendix.

${ }^{9}$ Proposition 3 below shows that setting $\tau=R(k)$ is indeed optimal.
} 
$\tau=R(k)$, equation (10) implies $\frac{V}{\delta}=p V^{H}+(1-p) V^{L}$, which gives the maximum feasible rate of growth of equity. This is a necessary condition for efficiency as long as $V^{H}<\tilde{V}$, as indicated by Proposition 3. In the region of values where $V^{H} \geq \widetilde{V}$, there is some degree of indeterminacy on the optimal repayment policy. In particular, among the optimal repayment policies is the one that requires the entrepreneur to transfer all the cash flows to the lender until his value reaches $\widetilde{V}$, and to pay nothing thereafter.

Proposition 3 (i) The following condition is necessary for an optimal contract: if $V^{H}<\widetilde{V}$ then $\tau=R(k)$; (ii) It is optimal to set $\tau=R(k)$ for all $V<\widetilde{V}$.

Proof. For part (i), consider the case where $V^{H}<\widetilde{V}$. If $\tau<R(k)$, then $V^{H}$ and $\tau$ can be increased in a way that all constraints are still satisfied. This results in a strictly higher value for $W\left(V^{H}\right)$ and, correspondingly, a higher current firm value $W(V)$. Part (ii) follows immediately from the monotonicity of the value function.

\subsection{The Evolution of Equity.}

The optimal contract generates a stochastic process $\left\{V_{t}\right\}$ for the value of the entrepreneur. In this section we characterize its evolution. By Proposition 3, optimality implies a unique path for $V_{t}$ as long as $V^{H}(V)<\widetilde{V}$. When this condition does not hold, the path followed by $V_{t}$ depends on the choice of dividend distribution policy. In this section we choose to characterize the evolution of equity in the case in which $\tau=R(k)$ for all $V<\widetilde{V} .{ }^{10}$ This choice, along with the flow equation (2), implies that $V_{t}<p V_{t}^{H}+(1-p) V_{t}^{L}$, so that $\left\{V_{t}\right\}$ is a submartingale. This process has two absorbing sets, $V_{t}=0$ and $V_{t} \geq \widetilde{V}$. Eventually, either the first one is reached and the firm is liquidated, or the second one is reached and borrowing constraints cease forever. In the set $0<V_{t}<V_{r}$, the randomization described above takes place. We will now characterize the process for $V_{r} \leq V_{t}<\widetilde{V}$.

Using the incentive compatibility constraint (3) we can define an indirect profit

\footnotetext{
${ }^{10}$ All relevant properties are independent of the selection used. In particular, this is true for the optimal capital advancement policy $k(V)$, which is uniquely determined.
} 
function as follows:

$$
\begin{aligned}
\Pi\left(V^{H}-V^{L}\right) \equiv & \max p R(k)-k \\
& \text { s.t. } R(k) \leq \delta\left(V^{H}-V^{L}\right) .
\end{aligned}
$$

It is straightforward to show that $\Pi$ is strictly concave and strictly increasing for $V^{H}-V^{L}<\frac{R\left(k^{*}\right)}{\delta}$, and constant at the value $p R\left(k^{*}\right)-k^{*}$ thereafter. For $V \geq V_{r}$, the optimal contract design problem can be conveniently restated as

$$
\begin{gathered}
W(V) \equiv \max _{V^{H}, V^{L}} \Pi\left(V^{H}-V^{L}\right)+\delta\left[p W\left(V^{H}\right)+(1-p) W\left(V^{L}\right)\right] \\
\text { s.t. } V=\delta\left(p V^{H}+(1-p) V^{L}\right) .
\end{gathered}
$$

Since $W$ is concave, it is almost everywhere differentiable. Let $\lambda$ denote the Lagrange multiplier for the constraint. Then, the necessary conditions for optimality are given by

$$
\begin{array}{r}
\Pi^{\prime}\left(V^{H}-V^{L}\right)+\delta p W^{\prime}\left(V^{H}\right)-\delta p \lambda=0 \\
-\Pi^{\prime}\left(V^{H}-V^{L}\right)+\delta(1-p) W^{\prime}\left(V^{L}\right)-\delta(1-p) \lambda=0
\end{array}
$$

and by the envelope condition

$$
\lambda=W^{\prime}(V) .
$$

Together with Lemma 1, Proposition 2 implies that $\Pi^{\prime}\left(V^{H}-V^{L}\right)>0$ for $V<\widetilde{V}$. Using (5), (6) and (7) we obtain that

$$
W^{\prime}\left(V^{H}\right)<W^{\prime}(V)<W^{\prime}\left(V^{L}\right) .
$$

By concavity of the value function, it follows that

$$
V^{L}<V<V^{H}
$$

The results reached so far are summarized in Proposition 4.

Proposition 4 Let $V \in\left[V_{r}, \widetilde{V}\right)$. If $\tau=R(k)$ the following holds: (i) $V^{L}<V<$ $V^{H}$; (ii) $V<p V^{H}+(1-p) V^{L}$.

Value increases with a good shock and decreases with a bad shock. Moreover, as Proposition 5 shows, the process $\left\{V_{t}\right\}$ displays persistence. Lower values in a given period result in lower future values. 
Proposition 5 The policy functions $V^{H}(V)$ and $V^{L}(V)$ are nondecreasing in $V$.

Using (2), (3), and $\tau=R(k)$, the law of motion for $V$ can be explicitly obtained:

$$
V^{L}=\frac{V-p R(k)}{\delta}, V^{H}=\frac{V+(1-p) R(k)}{\delta} .
$$

This shows that in general there is an asymmetry between the change in equity value following good and bad shocks. In particular, if $p$ and $\delta$ are large, $V-V^{L}>V^{H}-V$, while the opposite will hold if $p<1 / 2$. Figure 3 shows the qualitative behavior of the functions $V^{H}(V)$ and $V^{L}(V)$. We already know that, for $V<V_{r}$, randomizing over the liquidation decision emerges as an optimal strategy. By Proposition 5 these functions are nondecreasing for $V \geq V_{r}$. As illustrated in the figure, starting from an equity value $V_{0} \in\left[V_{r}, \widetilde{V}\right)$ a finite sequence of high shocks leads to $\tilde{V}$. From the same value, a sequence of low shocks leads to the randomization region.

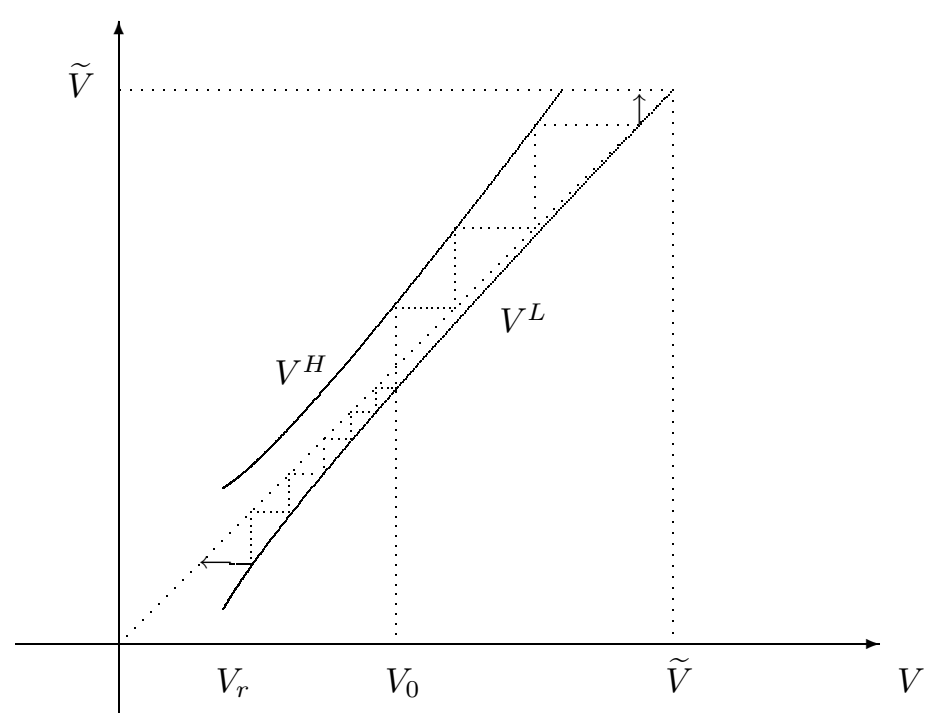

Figure 3: The Dynamics of Equity.

\subsection{The Optimal Capital Advancement Policy.}

In subsection 2.1 we have shown that, under symmetric information, it would always be optimal for the lender to provide the entrepreneur with the unconstrained efficient amount of capital. However, this ceases to be the case when the lender 
cannot observe the firm's cash flows. Proposition 2 establishes that borrowing constraints are indeed a feature of the optimal long-term contract under asymmetric information.

An immediate consequence of Proposition 2 is that the allocation of capital increases with $V$ over some range of values. The numerical results discussed below suggest that this range may include most of the domain, yet general properties are hard to derive. Indeed, monotonicity does not hold throughout the whole range of values. Proposition 6 shows that as equity values get close to the randomization region, capital advancements actually increase. There is an intuitive explanation for this result. As a consequence of the option of liquidation, risk taking is encouraged in a neighborhood of the exit region. This is reflected both by the randomized liquidation decision and the increase in capital advancements. At the other extreme, capital advancements increase with $V$ in a neighborhood of $\widetilde{V}$.

Proposition 6 There exist value entitlements $V^{*}$ and $V^{* *}$, with $V_{r}<V^{*} \leq V^{* *}<$ $\widetilde{V}$, such that:

1. the policy function $k(V)$ is non-increasing for $V \in\left[V_{r}, V^{*}\right]$;

2. the policy function $k(V)$ is non-decreasing for $V \in\left[V^{* *}, \widetilde{V}\right]$.

We now turn to the results of our numerical experiment. ${ }^{11}$ Figure 4 shows how the advancement of working capital responds to good and bad realizations of the revenue process. The higher curve corresponds to the growth rate of capital, conditional on success, i.e. $\frac{k\left(V^{H}\right)}{k(V)}$. The lower one corresponds to $\frac{k\left(V^{L}\right)}{k(V)}$. Even though $k(V)$ is not monotone, in the case of our experiment success is always followed by an increase in the capital invested, while failure always triggers a decline. Also, notice how the magnitude of the response of investment to cash-flow innovations changes with $V$. Percentage changes in capital tend to be larger (in absolute value) for small values of $V$ and show a tendency to decline as $V$ increases. When $V$ equals the threshold $\widetilde{V}$, the level of capital invested is independent of cash-flows.

Our results suggest that for a panel of firms obtaining external finance through our contract, investment-cash flow sensitivity would decrease with both size (as

\footnotetext{
${ }^{11}$ The parameter values are the same as those listed in Section 4.
} 


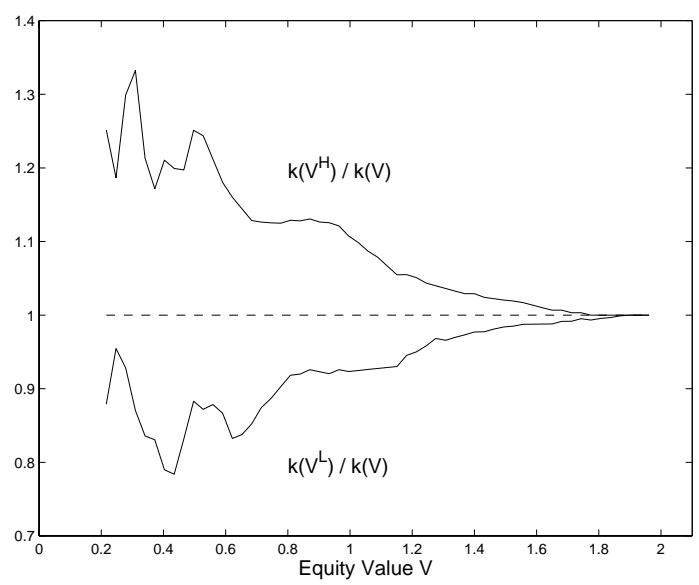

Figure 4: Growth rates of capital conditional on revenue realization.

measured by the level of working capital invested) and age. This relation between sensitivity and size obtains because, as we have just argued, $k(V)$ is monotone for most values of $V$. The relationship with age stems from the positive correlation between age and size, outlined in the next section. ${ }^{12}$

\section{Firm Growth and Survival.}

This section considers some of the implications of the model for firm dynamics. Since detailed implications are very difficult to derive, we complement our analysis with some numerical results, which suggest that our model is consistent with a set of widely established empirical findings. We proceeded to draw a large number of independent sample paths for firm shocks, assuming all firms start at the same initial value $V_{0} \in\left[V_{r}, \widetilde{V}\right)$. Figure 5 summarizes the results of our simulation exercise. ${ }^{13}$

\footnotetext{
${ }^{12}$ In most of the empirical literature we refer to (Fazzari, Hubbard and Petersen [15] and Gilchrist and Himmelberg [18], for instance), investment is regressed on cash-flows and on a predictor of the expected marginal return of capital. In the case of our model, the equity value $V_{t}$ is a sufficient statistic for $k_{t}$ and is therefore a natural candidate for the role of control. The coefficient of cash flows will be positive and statistically significant as long as there is at least one period lag between investment and the control. This is actually the case in all regression specifications we are aware of. Conversely, the coefficient will be zero if the two variables are contemporaneous. We thank Joao Gomes for pointing this out to us.

${ }^{13}$ Our parametric assumptions are as follows. We set $R(k)=k^{2 / 5}, p=0.5, \delta=0.99$, and $S=1.5$. The discount rate yields an interest rate $\frac{1}{\delta}-1=1 \%$, which we interpret as the quarterly interest rate. The time series obtained have been aggregate to generate yearly data, and then
} 
Throughout this section we identify firm size with its working capital $k$. Sample paths either end with exit or in the unconstrained region. Since $k<k^{*}$ whenever $V<\widetilde{V}$, in average surviving firms grow with age. Firm age and size are positively correlated. Both mean and variance of the growth rate decrease systematically with age, and thus with size. These predictions are qualitatively in line with the findings of the recent empirical literature on firm dynamics. In particular, we refer the reader to work by Evans [14] and Hall [20].


Figure 5: Dynamics of Growth and Survival.

As mentioned in the introduction, there is widespread agreement on the finding that failure rates decrease with firm age and size. Moreover, conditional on age, a larger size implies a lower failure rate. Our model predicts that the conditional probability of survival increases with the value of the firm's equity $V$.

averaged in the cross-section. 
Proposition 7 Let $T$ be the stopping time corresponding to firm exit. Then, for every $t, \operatorname{Pr}(T>t \mid V)$ is strictly increasing in $V$ for $V<\widetilde{V}$ and $\operatorname{Pr}(T=\infty \mid V)=1$ for $V \geq \widetilde{V}$.

A firm may exit only after having reached the randomization region. This occurs as the consequence of a series of negative shocks. Since the continuation values $V^{H}$ and $V^{L}$ are weakly increasing in current value, any history of shocks - including the outcome of randomization - that leads a firm with an initial value $V$ to exit will lead a firm with a lower initial value to exit too. As in Jovanovic [22], selection occurs as a consequence of exit. The values of older firms will tend to be higher, thus reducing the probability of exit. Given that the initial value $V_{0}>V_{r}$, it may take a few periods for firms to exit. We conjecture that our model implies that hazard rates are likely to increase in the early stages of the firm lifetime and decrease thereafter. Figure 5 shows that our simulations are consistent with this conjecture. In addition, for a range of values where $k$ is increasing in $V$, our model predicts that failure rates decrease with firm size, both unconditionally and controlling for age.

\section{Long vs. Short-Term Contracts, Debt Limit, and Forgiveness.}

Can a long term lending contract be replicated by a sequence of short term contracts? This section provides a general answer to this question. An optimal lending contract defines a continuous frontier of values $B(V)=W(V)-V$ on the domain of equity values $\mathcal{V}$. The level of debt $B$ is a sufficient statistic if and only if the function $B(V)$ is strictly decreasing on $\mathcal{V}$. In such case, the inverse function $V(B)$ gives the entrepreneur's value as a function of the outstanding debt. The optimal contract can thus be formulated as a debt management problem, as in Gertler [16]. More precisely, letting $\bar{B}=\sup _{V \in \mathcal{V}} B(V)$, the optimal contract satisfies the following 
dynamic programming problem:

$$
\begin{aligned}
& V(B)=\max _{k, \tau, B^{H}, B^{L}} p(R(k)-\tau)+\delta\left[p V\left(B^{H}\right)+(1-p) V\left(B^{L}\right)\right] \\
& \text { s.t. } B^{L}, B^{H} \leq \bar{B}, \\
& \quad B=p \tau-k+\delta\left[p B^{H}+(1-p) B^{L}\right], \\
& \quad \tau \leq \delta\left(V\left(B^{H}\right)-V\left(B^{L}\right)\right) .
\end{aligned}
$$

In the region where borrowing constraints are effective, $W^{\prime}(V)=B^{\prime}(V)+1>0$. This implies that $B^{\prime}(V)>-1$ and thus $V^{\prime}(B)<-1$. As a consequence, $V\left(B^{H}\right)-$ $V\left(B^{L}\right)>B^{L}-B^{H}>0$. Substituting the incentive constraint (11) in (10), we obtain that

$$
\begin{aligned}
B & =p \tau-k+\delta B^{L}+\delta p\left(B^{H}-B^{L}\right) \\
& >p \tau-k+\delta B^{L}-\delta\left(V\left(B^{H}\right)-V\left(B^{L}\right)\right) \\
& =-k+\delta B^{L}
\end{aligned}
$$

where the last equality holds since the incentive constraint binds. From this inequality it follows that

$$
B^{L}<\frac{B+k}{\delta}
$$

The right hand side of (12) corresponds to the outstanding debt in the following period, if no payment was made. This inequality implies that the contract provides explicitly for some debt forgiveness. This is of course compensated by debt falling by less than the value of repayment in the high state. These remarks apply even when $B(V)$ is not strictly decreasing on all its domain, when restricted to the region where it is.

It is easy to see that by rolling over the debt, a sequence of short term contingent debt contracts is sufficient to implement the solution of the above dynamic program. There is no need for a long term contract. The condition that $B(V)$ is strictly decreasing in the domain of the contract is equivalent to the contract being renegotiation-proof. Hence, renegotiation proofness characterizes financial contracts that can be implemented by one-period contingent debt contracts.

This conclusion does not necessarily apply to our model, since for low values of equity it is possible that $B^{\prime}(V)>0$. This is the case, for example, when $S=0$ 
and $R^{\prime}(0)=\infty$. However, for a sufficiently high scrap value, $B(V)$ will be strictly decreasing. To see this, first note that by concavity $W^{\prime}(V)$ is decreasing, and so is $B^{\prime}(V)=W^{\prime}(V)-1$. Hence, $B(V)$ will be strictly decreasing if and only $W^{\prime}(V) \leq 1$ in the randomization area. This will occur for high levels of $S .{ }^{14}$ Incidentally, this condition is equivalent to saying that the liquidation decision is renegotiation-proof.

As indicated above, there is a maximum level of sustainable debt $\bar{B}$, which corresponds to the lowest level of equity in the region where $B^{\prime}(V)<0$. There are two possible cases: the corresponding value of equity is either zero or positive. In the first case, the contract is renegotiation proof and $\bar{B}=S$. The entrepreneur's debt is fully collateralized. In the second case, $\bar{B}>S$. The debt can exceed the value of collateral.

The results of this section are summarized in the following proposition.

Proposition 8 i) The optimal contract can be implemented by a sequence of oneperiod contingent debt contracts if and only if it is renegotiation-proof. ii) in any region where there is no incentive for renegotiation the contract involves debt forgiveness in the low state. iii) The maximum sustainable debt $\bar{B} \geq S$, where $\bar{B}=S$ if and only if the contract is renegotiation-proof.

\section{The Role of Collateral.}

The scrap value $S$ constitutes the resale value of the project and thus its collateral. In this section we investigate how an increase in the value of $S$ affects the lending contract.

Obviously, a larger $S$ implies a larger surplus $W$ for every $V<\widetilde{V}$. In turn, this implies that the set of pairs $\left(I_{0}, M\right)$ that insure financial feasibility is also larger. Our analysis in Section 7 also implies that when the lending market is competitive a larger collateral translates into an higher initial equity value $V_{0}$.

A more subtle yet interesting implication can be inferred by inspection of Figure 6. ${ }^{15}$ As shown in the top panel, an increase in $S$ decreases the degree of concavity

\footnotetext{
${ }^{14}$ It is obviously true for $S=\widetilde{W}$, since in that case $W(V)=\widetilde{W}$ and $W^{\prime}(V)=0$. By continuity, it will also hold for lower $S$.

${ }^{15}$ The right-most panel of the figure is the result of a simulation exercise conducted as described
} 
of the function $W(V)$. As a consequence, one may expect the capital advancement $k$ to increase for every $V<\widetilde{V}$. There is an intuitive explanation. As explained in Section 3.3, higher capital advancements are costly since by lowering $V^{L}$ they increase the risk of future (inefficient) liquidation. A larger collateral $S$ makes this risk less costly, resulting in a higher capital advancement. Figure 6 illustrates this effect. In the case of our numerical experiment, the elasticity of capital advancement to changes in the value of collateral can be larger than 1 .
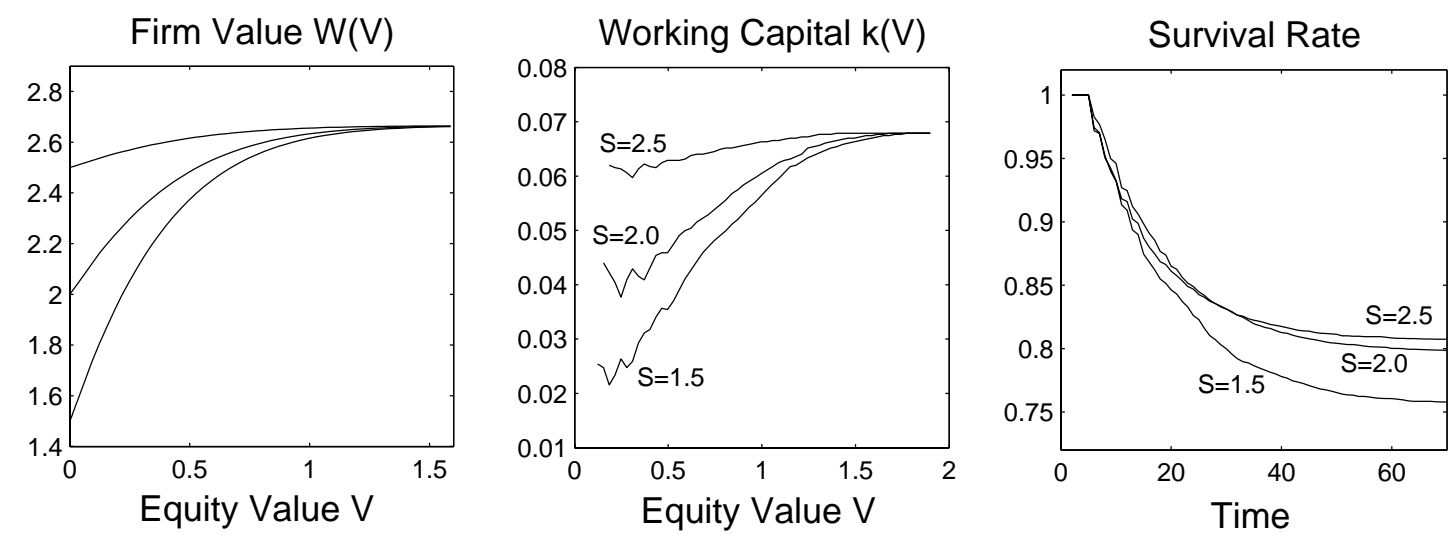

Figure 6: Comparative Statics with respect to the value of collateral.

It is also of interest to study the effect of different collateral values on firm survival. In this respect, the analysis that we have conducted so far is inconclusive. While a larger $S$ makes liquidation more appealing, it also has the effects of increasing the initial equity $V_{0}$ and the continuation value of the project. ${ }^{16}$ Figure 6 illustrates that from our simulation exercise does not emerge an ordering of the survival functions. However, in the limit survival increases with $S$.

in Section 4. The initial equity values were pinned down by assuming that the lending market is competitive.

${ }^{16}$ The analysis carried out in Section 7 implies that if the lending market is competitive, the initial equity $V_{0}$ is larger when the value function $W(V)$ is uniformly less concave. 


\section{Financial Feasibility.}

Our previous analysis did not consider the initial distribution of surplus. Letting $V_{0}$ denote the initial value to the entrepreneur, $B_{0}\left(V_{0}\right)=W\left(V_{0}\right)-V_{0}$ is the value to the lender. Given the entrepreneur's initial net worth $M<I_{0}$, the project requires an initial contribution from the lender $I_{0}-M$. The lender will be willing to provide financing to the entrepreneur, as long as $V_{0}$ satisfies

$$
\left[W\left(V_{0}\right)-V_{0}\right]-\left[I_{0}-M\right] \geq 0
$$

The entrepreneur will be willing to invest as long as $V_{0}>M$. The project is financially feasible if there exists an initial allocation of value $\left(B_{0}, V_{0}\right)$ such that both parties are willing to invest.

If the maximum sustainable debt $\bar{B}<I_{0}-M$, the project is not financially feasible. Otherwise, let $\underline{V}$ denote the largest $V_{0} \geq 0$ such that $B\left(V_{0}\right)=I_{0}-M$. The project is financially feasible if an only if $\underline{V} \geq M$. The value $\underline{V}$ also defines the equilibrium starting level of equity in a market with competing lenders. This initial equity $\underline{V}$ is strictly increasing in the net worth of the entrepreneur $M$.

It is instructive to examine again the role of collateral. As indicated above, for large collateral, $\bar{B}=B(0)$ and initial lending is constrained by the value of collateral. However, when the collateral is relatively low, initial lending will exceed its value. In the latter case, the contract cannot be implemented by one-period contingent debt. This suggests the importance of long term lending when the value of collateral is small compared to initial setup costs, which is the case for investments that involve large sunk costs.

\section{Unobservable Investment.}

This section considers an alternative source of moral hazard. We assume that the lender can monitor the outcome of the project each period but not the use of funds. The entrepreneur faces an outside opportunity that provides utility $V_{a}(k)$. We assume that $V_{a}$ is strictly increasing and strictly concave. The incentive compatibility 
constraint for this problem is given by

$$
p R(k)-\tau+\delta\left(p V^{H}+(1-p) V^{L}\right) \geq V_{a}(k)+\delta V^{L} .
$$

All our previous analysis still goes through, once we define

$$
\begin{aligned}
\Pi\left(V^{H}-V^{L}\right) \equiv & \max p R(k)-k \\
& \text { s.t. } V_{a}(k) \leq \delta p\left(V^{H}-V^{L}\right) .
\end{aligned}
$$

Our previous analysis uses only two properties of the indirect profit function, namely monotonicity and concavity. The first property is immediate from the above definition. Sufficient conditions for concavity are given in Lemma 2 in the appendix. Notice that in the special case where $V_{a}(k)=p R(k)$, the two indirect profit functions are identical.

\section{A Comparison to Incomplete Enforcement.}

Several papers in the literature on financing contracts consider an alternative formulation, where borrowing constraints result from incomplete enforcement. There are no informational asymmetries, but borrowers can default on their debts and take an outside option. This section provides a sharp distinction between the two alternative approaches.

The incomplete enforcement model that we describe is the natural counterpart to our moral hazard model. Take the same revenue function $R(k)$ and process for the shocks. There is no asymmetric information, so the lender observes the outcome of the project. However, the entrepreneur can default by keeping the revenues and not paying back the loan. The project is then liquidated, giving the lender the liquidation value $S$. By defaulting, the entrepreneur gets a value $R(k)$ if the productive state had realized. Otherwise, there is no value from defaulting.

Letting $V^{H}$ denote the continuation value in the productive state, the no-default constraint is given by

$$
R(k) \leq \delta V^{H}
$$


Define now the indirect profit function as

$$
\begin{array}{r}
\Pi\left(V^{H}\right) \equiv \max _{k} p R(k)-k \\
\text { s.t. } R(k) \leq \delta V^{H} .
\end{array}
$$

The optimal no-default contract solves the following dynamic programming equation:

$$
\begin{gathered}
W(V)=\max _{V^{H}, V^{L}} \Pi\left(V^{H}\right)+\delta\left[p W\left(V^{H}\right)+(1-p) W\left(V^{L}\right)\right] \\
\text { s.t. } V \geq \delta\left(p V^{H}+(1-p) V^{L}\right)
\end{gathered}
$$

This problem is the analogue of (P3). The only difference is that $V^{L}$ is not an argument of the indirect profit function. First order conditions for the choice of continuation values are given by

$$
\begin{array}{r}
\Pi^{\prime}\left(V^{H}\right)+\delta p W^{\prime}\left(V^{H}\right)-\delta p \lambda=0 \\
W^{\prime}\left(V^{L}\right)-\lambda=0 .
\end{array}
$$

Using the envelope condition $\lambda=W^{\prime}(V)$, it follows that

$$
W^{\prime}\left(V^{H}\right)<W^{\prime}(V)=W^{\prime}\left(V^{L}\right)
$$

which implies that

$$
V^{L}=V<V^{H}
$$

The equity value increases in response to good shocks but never decreases! As a consequence, the firm never shrinks nor exits.

\section{Final Remarks.}

There exist a large variety of lending contracts with implicit and unwritten contingencies and clauses. This makes it very difficult to assess directly the empirical implications of borrowing constraints. Existing empirical tests are indirect, focusing mostly on the sensitivity of investment to cash-flows and on other features of firm dynamics. It is our view that theory can contribute to this debate through a better understanding of borrowing constraints and their empirical implications. 
This requires theories that derive borrowing constraints from first principles and are suitable for the analysis of firm dynamics. Gertler [16] was clearly a move in this direction. Our paper contributes to this research program.

We have chosen to keep the model as simple as possible, with the minimal elements needed to derive endogenous borrowing constraints in a dynamic setup. In spite of its simplicity, our model matches most of the qualitative properties of firm dynamics that have been recently documented. Moral hazard thus seems to be a good foundation for the analysis of borrowing constraints.

Our model is also useful to better understand the value and importance of long term lending contracts. We have shown that projects with high collateral are renegotiation-proof and are implementable through a sequence of one-period (contingent) loans. Borrowing is limited by the value of the collateral itself. In contrast, when the collateral is low relative to the total value of the project, initial lending can exceed its value. In the latter case, the optimal contract requires commitment of the lender to no-renegotiation and cannot be implemented by a sequence of short-term contracts. Long term lending is thus more valuable for investments that involve high sunk costs.

The restriction to renegotiation-proof contracts can limit lending opportunities. In some cases, it could lead to the extreme of making the project financially infeasible. The ability of lenders to commit to long term contracts can thus have considerable value. The same can be said of institutions that facilitate reputation building and the establishment of long-term relationships.

It is interesting to compare the implications of our model to theories of incomplete contracts where borrowing constraints arise from incomplete enforcement, as in Albuquerque and Hopenhayn [1]. We have shown that, differently from our setup, in the incomplete enforcement analogue of our model firm size never decreases. In the environment studied by Albuquerque and Hopenhayn [1], the stochastic structure is such that firm size does decrease in response to low productivity shocks. Conditional on a given productivity shock, however, size never decreases. While these these predictions are difficult to test, we still conjecture that the two classes of models would differ considerably in their quantitative implications. 
In the recent past, many scholars have conjectured the existence of a causation link between financing constraints and the sensitivity of investment to cash flows. In this paper we have provided a model that endogenously generates this link. However, the observed sensitivity may also be due to a simple selection process, as in the models of Jovanovic [22] and Alti [2]. In either one of these papers, entrepreneurs start out not knowing the productivity of their firms and learn about it by observing the cash-flows realizations. With Bayesian learning, an increase (decrease) in cashflows prompts an upward (downward) revision of the firm's expected productivity level, and therefore adjustments in capital expenditures of the same sign. It is of obvious interest to develop testable predictions that can help to discriminate between the two theories. We will discuss two potential candidates. In our model the value of equity is a sufficient statistic for investment. The investment-cash-flow sensitivity varies with age only because age is correlated with size. Controlling for size, age should not matter. In the cases of Jovanovic and Alti, exactly the opposite occurs. The investment-cash flow sensitivity varies with size only because it is correlated with age. Further, consider the role of sunk costs. In Jovanovic [22], the level of sunk costs affects the degree of selection, but should not have a considerable impact on firm dynamics. In contrast, in our model higher sunk costs imply that firms start smaller and thus exhibit higher average rates of growth. Our analysis also suggests that a higher liquidation value can lead to higher variance in growth rates.

We have assumed that both lender and borrower are risk neutral. In spite of this, risk considerations arise in the optimal contract design as a result of the interaction of limited liability and a concave revenue function. The resulting degree of risk aversion is not constant and depends on the entrepreneur's equity. We find that risk taking is encouraged at the extremes, close to the liquidation area and for large values of equity. In our model the project and its risk are taken exogenously. Allowing for risk to be a choice variable is an interesting direction in which our theory could be extended.

There are many other interesting extensions. Multiple shocks can be easily accommodated, as in Quadrini [25]. A model with partial liquidation (downsizing) has been studied by DeMarzo and Fishman [11]. The dynamics of capacity uti- 
lization may be studied adopting the timing of Gertler [16]. Finally, we suggest that our model may have interesting applications in macroeconomics. Starting with Bernanke and Gertler [7], there has been a growing interest in understanding to what extent various forms of frictions in financial markets may generate and/or amplify macroeconomic fluctuations. However, the financial arrangements that are considered in this literature are never intertemporally optimal, meaning that contracts' provisions are not contingent on all public information. The only exception is recent work by Cooley, Quadrini, and Marimon [10], that embed the model by Albuquerque and Hopenhayn [1] in a general equilibrium framework. It would definitely be of interest to perform a similar exercise with the model developed in this paper, and then contrast the predictions generated by the two approaches. 


\section{A Appendix - Proofs and Lemmas.}

\section{Proposition 1.}

Proof. All but one of the statements of the proposition were proven in the text. It is left to show that $W(V)$ is strictly increasing for $V<\widetilde{V}$. By contradiction, assume that there exists a pair $\left(V^{\prime}, V\right)$ such that $V^{\prime}<V<\widetilde{V}$ and $W\left(V^{\prime}\right)=W(V)$. Then, by concavity of the value function it must be that $W\left(V^{\prime}\right)=W(V)=\widetilde{W}$, which is a contradiction.

\section{Proposition 2.}

Proof. i) It follows from standard dynamic programming arguments, since (P1) defines a concave programming problem which is strictly concave in $k$. ii) By contradiction, assume that there exists some $V<\widetilde{V}$ such that $k(V)=k^{*}$. Then, since $\widetilde{W}=\frac{p R\left(k^{*}\right)-k^{*}}{1-\delta}, W(V)=(1-\delta) \widetilde{W}+\delta\left[p W\left(V^{H}\right)+(1-p) W\left(V^{L}\right)\right]$. By Proposition 1 , it must be the case that $W(V)<\widetilde{W}$, and therefore either $V^{H}<\widetilde{V}$, or $V^{L}<\tilde{V}$, or both. If $W^{\prime}\left(V^{H}\right)<W^{\prime}\left(V^{L}\right)$, consider lowering slightly $k$ and $\tau$ in such a way that $R(k)-\tau$ does not change. The marginal effect of this change on the surplus is zero, since $p R^{\prime}\left(k^{*}\right)=1$. However, it has the effect of relaxing the incentive compatibility constraint. By Jensen inequality, total surplus can be increased by lowering $V^{H}$ and raising $V^{L}$, in such a way that the promise-keeping constraint still hold. If $W^{\prime}\left(V^{H}\right)=W^{\prime}\left(V^{L}\right)$ then the value function is linear over the range $\left(V^{L}, V^{H}\right)$. By Proposition 1 , it must be that $V^{H}<\widetilde{V}$. Therefore, by Proposition 3 it follows that $\tau=R\left(k^{*}\right)$. Thus, $p V^{H}+(1-p) V^{L}=\frac{V}{\delta}$. By linearity, it follows that $p W\left(V^{H}\right)+(1-p) W\left(V^{L}\right)=W\left(\frac{V}{\delta}\right)$. On the other hand, $W(V)<\widetilde{W}$ implies $\left[p W\left(V^{H}\right)+(1-p) W\left(V^{L}\right)\right]>W(V)$. Summarizing, we have that $\left[p W\left(V^{H}\right)+(1-p) W\left(V^{L}\right)\right]=W\left(\frac{V}{\delta}\right)>W(V)>\left[p W\left(V^{H}\right)+(1-p) W\left(V^{L}\right)\right]$, which is a contradiction. iii) Again by Proposition $1, W(V)=\frac{p R\left(k^{*}\right)-k^{*}}{1-\delta}$ for $V \geq \tilde{V}$. The only way such surplus can be achieved is by setting $k(V)=k^{*}$.

Lemma 1 When $\tau=R(k)$, then the IC constraint (3) binds for every $V<\widetilde{V}$.

Proof. By Proposition 2, $V<\tilde{V}$ implies that $k(V)<k^{*}$. For the sake of contradiction, assume there exists $V$ such that $R(k)<\delta\left(V^{H}-V^{L}\right)$. Then by strict 
monotonicity of the revenue function it is possible to increase the surplus of the match strictly just by raising $k$. But this contradicts optimality.

\section{Proposition 5.}

Proof. We begin by proving that the function $V^{H}(V)$ is nondecreasing. Take any $V$, $V<\widetilde{V}$. Consider raising $V$. By concavity of the value function, $W^{\prime}(V)$ decreases weakly. By contradiction, assume that $V^{H}$ is now strictly lower. It follows that $W^{\prime}\left(V^{H}\right)$ is weakly higher. For constraint (2) to hold, $V^{L}$ must increase strictly. Since $\Pi$ is strictly concave in the relevant range, $\Pi^{\prime}\left(V^{H}-V^{L}\right)$ must also increase strictly. However, this contradicts condition (5). The proof of monotonicity of $V^{L}(V)$ is very similar. Take any $V, V<\widetilde{V}$. Consider raising $V$. By concavity of $W, W^{\prime}(V)$ decreases weakly. By contradiction, assume that $V^{L}$ is now strictly lower. It follows that $W^{\prime}\left(V^{L}\right)$ is weakly higher. For constraint (2) to hold, $V^{H}$ must increase strictly. Since $\Pi$ is strictly concave in the relevant range, $\Pi^{\prime}\left(V^{H}-V^{L}\right)$ increases strictly. However, this contradicts condition (6).

\section{Proposition 6.}

Proof. Combining conditions (5) and (6), one obtains that a necessary condition for the optimal contract is $p(1-p)\left(W^{\prime}\left(V^{L}\right)-W^{\prime}\left(V^{H}\right)\right)=\Pi^{\prime}\left(V^{H}-V^{L}\right)=1-\frac{1}{p R^{\prime}(k)}$.

1) By Proposition $5, V^{L}\left(V_{r}\right)<V_{r}$. By continuity of the function $V^{L}(\cdot)$, there exists $V>V_{r}$ such that $V^{L}(V)<V_{r}$. Combining this fact with monotonicity of $V^{H}(\cdot)$ and concavity of the value function yields the prediction that $\left(W^{\prime}\left(V^{L}\right)-W^{\prime}\left(V^{H}\right)\right)$ is non-decreasing and thus $k(\cdot)$ non-increasing on $\left[V_{r}, V\right]$.

2) We know that $V^{H}(\widetilde{V})>\widetilde{V}$. By continuity of the function $V^{H}(\cdot)$, there exists $V<\widetilde{V}$ such that $V^{H}(V)>\widetilde{V}$. Combining this fact with monotonicity of $V^{L}(\cdot)$ and concavity of the value function yields the prediction that $\left(W^{\prime}\left(V^{L}\right)-W^{\prime}\left(V^{H}\right)\right)$ is non-increasing and thus $k(\cdot)$ non-decreasing on $[V, \widetilde{V}]$.

Lemma 2 The sign of $\Pi^{\prime \prime}\left(V^{H}-V^{L}\right)$ is given by the sign of $\frac{p R^{\prime \prime}(k)}{p R^{\prime}(k)-1}-\frac{V_{0}^{\prime \prime}(k)}{V_{0}^{\prime}(k)}$.

Proof. It is immediate, by implicit differentiation of $\Pi$. 


\section{References}

[1] Rui Albuquerque and Hugo Hopenhayn. Optimal lending contracts and firm dynamics. Review of Economic Studies, forthcoming.

[2] Aydogan Alti. How sensitive is investment to cash flow when financing is frictionless? Journal of Finance, 58:707-22, 2003.

[3] Andrew Atkeson. International lending with moral hazard and risk of repudiation. Econometrica, 59:1069-89, 1991.

[4] Andrew Atkeson and Robert Lucas. On efficient distribution with private information. Review of Economic Studies, 59:427-53, 1992.

[5] David B. Audretsch. New-firm survival and the technological regime. Review of Economics and Statistics, 73:441-50, 1991.

[6] John Baldwin. The Dynamics of Industrial Competition. Cambridge University Press, Cambridge, MA.

[7] Ben Bernanke and Mark Gertler. Agency costs, net worth and business fluctuations. American Economic Review, 79:14-31, 1989.

[8] Patrick Bolton and David S. Scharfstein. A theory of predation based on agency problems in financial contracting. American Economic Review, 80:93-105, 1990.

[9] Josef Bruderl, Peter Preisendorfer, and Rolf Ziegler. Survival chances of newly founded business organizations. American Sociological Review, 57:227-42, 1992.

[10] Thomas F. Cooley, Ramon Marimon, and Vincenzo Quadrini. Aggregate consequences of limited contract enforceability. Stern School of Business, New York University, 2001.

[11] Peter DeMarzo and Michael Fishman. Optimal long-term financial contracting with privately observed cash flows. Graduate School of Business, Stanford University, 2001. 
[12] Timothy Dunne, Mark Roberts, and Larry Samuelson. Patterns of firm entry and exit in us manufacturing industries. Rand Journal of Economics, 19:495$515,1988$.

[13] Timothy Dunne, Mark Roberts, and Larry Samuelson. The growth and failure of us manufacturing plants. Quarterly Journal of Economics, 104:671-98, 1989.

[14] David Evans. The relationship between firm growth, size and age: Estimates for 100 manufacturing firms. Journal of Industrial Economics, 35:567-81, 1987.

[15] Steven Fazzari, Glenn Hubbard, and Bruce Petersen. Financing constraints and corporate investment. Brooking Papers on Economic Activity, 1:141-206, 1988.

[16] Mark Gertler. Financial capacity and output fluctuations in an economy with multi-period financial relationships. Review of Economic Studies, 59:455-72, 1992.

[17] Mark Gertler and Simon Gilchrist. Monetary policy, business cycles, and the behavior of small manufacturing firms. Quarterly Journal of Economics, 109:30940, 1994.

[18] Simon Gilchrist and Charles Himmelberg. Evidence on the role of cash flow for investment. Journal of Monetary Economics, 36:541-72, 1994.

[19] Edward Green. Lending and the smoothing of uninsurable income. In Contractual Arrangements for Intertemporal Trade. University of Minnesota Press, Minneapolis, MN, 1987.

[20] Bronwyn Hall. The relationship between firm size and firm growth in the us manufacturing sector. Journal of Industrial Economics, 35:583-606, 1987.

[21] Glenn Hubbard. Capital market imperfection and investment. Journal of Economic Literature, 36:193-225, 1998.

[22] Boyan Jovanovic. Selection and the evolution of industry. Econometrica, 50:649-70, 1982. 
[23] Albert Marcet and Ramon Marimon. Communication, commitment, and growth. Journal of Economic Theory, 58:219-49, 1992.

[24] Gabriel Perez-Quiros and Alan Timmermann. Firm size and cyclical variations in stock returns. Journal of Finance, forthcoming.

[25] Vincenzo Quadrini. Investment and default in optimal financial contracts with repeated moral hazard. Stern School of Business, New York University, 2000.

[26] Roy Radner. Repeated principal agent games with discounting. Econometrica, 53:1173-98, 1985.

[27] William Rogerson. Repeated moral hazard. Econometrica, 53:69-76, 1985.

[28] Steve Spear and Sanjay Srivastava. On repeated moral hazard with discounting. Review of Economic Studies, 54:599-617, 1987.

[29] Jeremy Stein. Agency, information, and corporate investment. Harvard University, 2001.

[30] Kenneth Troske. The dynamic adjustment of firm entry and exit in manufacturing and finance, insurance, and real estate. Journal of Law and Economics, 39:705-35, 1996.

[31] Toni Whited. Debt, liquidity constraints, and corporate investment: Evidence from panel data. Journal of Finance, 47:1425-60, 1992. 